\title{
Research on typical topologies of a tubular horizontal-gap passive magnetic levitation vibration isolator
}

\author{
Yiheng Zhou ${ }^{\text {a }}$, Baoquan Kou, Xiaobao Yang, Jun Luo and He Zhang \\ School of Electrical Engineering and Automation, Harbin Institute of Technology, China
}

\begin{abstract}
Magnetic levitation vibration isolators have attracted more and more attention in the field of high-precision measuring and machining equipment. In this paper, we describe a tubular horizontal-gap passive magnetic levitation vibration isolator. Four typical topologies of the tubular horizontal-gap passive magnetic levitation vibration isolator are proposed. The analytical expression of magnetic force is derived. The relationship between levitation force, force density, force ripple and major structural parameters are analysed by finite element method, which is conductive to the design and optimization of the tubular horizontal-gap passive magnetic levitation vibration isolator. The force characteristics of different topologies of the tubular horizontal-gap passive magnetic levitation vibration isolator are compared and evaluated from the aspect of force density, force ripple and manufacturability. In comparison with conventional passive magnetic levitation vibration isolators, the proposed tubular horizontal-gap passive magnetic levitation vibration isolator shows advantage in higher force density.
\end{abstract}

\section{Introduction}

High-precision measuring and machining technology is one of the most important research topics in modern industry. Besides the motion control strategies [1], vibration control is also one of the significant factors influencing the high-precision measuring and machining quality [2]. Owing to the advantages of wide vibration isolation bandwidth and low vibration transmissibility, active vibration isolation systems, which integrates actuators with passive gravity compensation devices, has great potential in high-precision application fields like microscope and lithography. The commonly used passive gravity compensation device includes mechanical springs, air bearings, and passive magnetic levitation vibration isolators. Among these methods, the mechanical spring is subject to mechanical coupling, which limits the positioning accuracy of the machining equipment. The air bearing is a good choice for gravity compensation because of its stable characteristics and mature technologies. However, the system structure will be very complex if air bearings are used in some measuring or machining equipment requiring a high vacuum condition [3], such as extreme ultraviolet lithography. In contrast, owing to the advantages of no mechanical contact, vacuum compatibility (no need of liquid or gas auxiliary equipment) and low natural frequency, passive magnetic levitation vibration isolators have drew increased interest in recent years [4-15].

\footnotetext{
${ }^{a}$ Corresponding author : sethvoler@163.com
} 
In this paper, a tubular horizontal-gap passive magnetic levitation vibration isolator (THPMLVI) is proposed, and a variety of typical topologies of the THPMLVI are studied to obtain higher high force density, which will reduce the volume of permanent magnet and the cost of THPMLVI. The paper is organized as follows. In Sec. 2, the typical topologies and operation principle of THPMLVI are introduced. In Sec. 3, the analytical expression of magnetic force is derived. In Sec. 4, the relationship between levitation force, force density, force ripple and major structural parameters are analysed by finite element method, which is conductive to the design and optimization of the THPMLV. The characteristics of different topologies of the THPMLV are compared and evaluated from the aspect of force density, force ripple and manufacturability.

\section{Typical topologies and operating principle}

The proposed tubular horizontal-gap passive magnetic levitation vibration isolator consists of three components, i.e., outer stator, mover, and inner stator, as shown in Fig. 1 (a). The mover consists of an aluminium plate and a magnet array. Both the outer and inner stators consist of an aluminium plate and a magnet array. There are four typical topologies of THPMLVI, i.e., NS-NS topology, HalbachNS topology, NS-Halbach topology, and Halbach-Halbach topology, as shown in Fig. 1. For the NSNS topology of THPMLVI, its mover consists of 3 radially magnetized magnets, and each of its stator consists of 4 radially magnetized magnets. For the Halbach-NS topology of THPMLVI, its mover consists of 3 radially magnetized magnets, and each of its stator consists of 4 radially magnetized magnets and 5 axially magnetized magnets. For the NS-Halbach topology of THPMLVI, its mover consists of 3 radially magnetized magnets and 8 axially magnetized magnets, and each of its stator consists of 4 radially magnetized magnets. For the Halbach-Halbach topology of THPMLVI, its mover consists of 3 radially magnetized magnets and 8 axially magnetized magnets, and each of its stator consists of 4 radially magnetized magnets and 5 axially magnetized magnets. The magnetization direction of the magnets are shown as arrows.

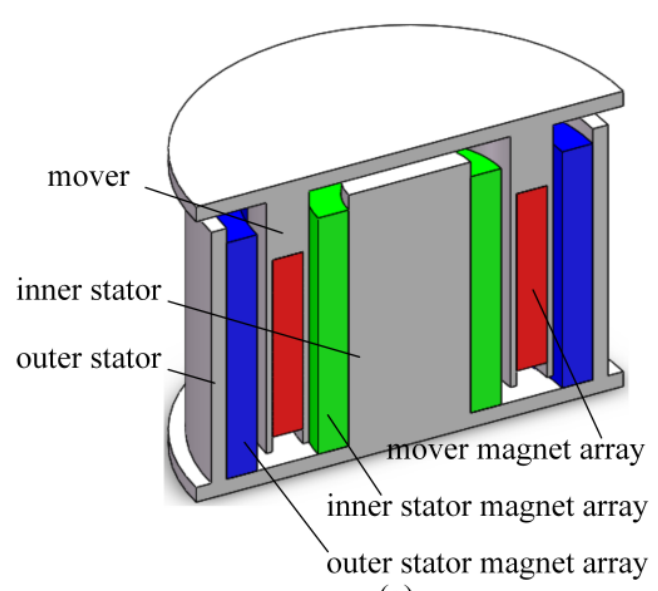

(a)

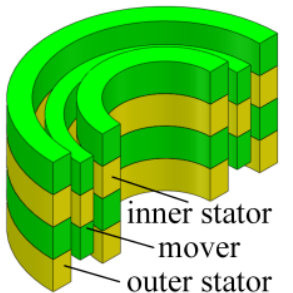

(b)

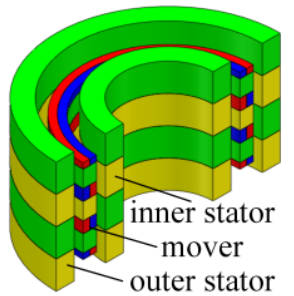

(d)

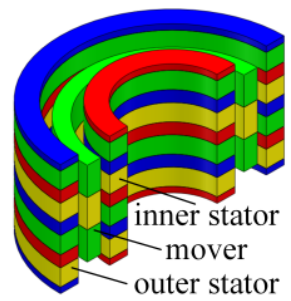

(c)

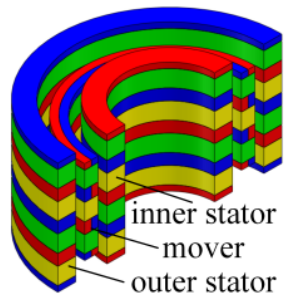

(e)

Figure 1. Typical topologies of the proposed THPMLVI. (a) basic structure, (b) NS-NS topology, (c) HalbachNS topology, (d) NS-Halbach topology, (e) Halbach-Halbach topology.

The operating principle of THPMLVI is based on the attraction and repulsion between permanent magnets. Take the NS-NS topology as example, the mover of THPMLVI is suspended above the stators by magnetic force between mover magnet array and stator magnet arrays. When the mover moves relative to the stators along the axial direction, the magnets with the same magnetization direction will generate attractive force with positive stiffness, and the magnets with opposite magnetization direction will generate repulsive force with negative stiffness, thus the total levitation 
force is near-constant. When the mover moves relative to the stators along the radial direction, due to the symmetry, the total levitation force is also near-constant. Through adopting the alternating magnetization direction and dual-stator structure, the $\mathrm{f}$ THPMLVI can generate near-constant levitation force and near-zero stiffness in six degree of freedom stroke, which is useful for improving the vibration isolation performance of active vibration isolation system.

In order to study the force characteristics of THPMLVI, the magnetic force between two mover magnet array and stator magnet arrays should be firstly calculated. According to the equivalent current model [16], the magnetic field generated by stator magnet arrays can be calculated as (1). Thus the magnetic force acting on the mover magnet array can be calculated as (2) [17]. The levitation force $F$, stiffness $k$, natural frequency $f$ of the THPMLVI can be expressed as (3). As shown in (3), compared to stiffness $k$, the force ripple $d F / F$ is a better indicator which can reflect its vibration isolation performance, because the natural frequency $f$ is directly related to vibration isolation ability. Therefore, force ripple is analysed instead of stiffness in the next section.

$$
\begin{gathered}
\boldsymbol{B}=\nabla \times \boldsymbol{A}, \quad \boldsymbol{A}=\frac{\mu_{0}}{4 \pi} \oint_{S} \frac{\boldsymbol{j}_{M}}{\left|r-r^{\prime}\right|} d a+\frac{\mu_{0}}{4 \pi} \oint_{V} \frac{\boldsymbol{J}_{M}}{\left|r-r^{\prime}\right|} d^{3} x \\
\boldsymbol{F}=\int_{S}\left(\boldsymbol{j}_{\boldsymbol{m}} \times \boldsymbol{B}\right) d s+\int_{V}\left(\boldsymbol{J}_{\boldsymbol{m}} \times \boldsymbol{B}\right) d v \\
k=\frac{d F}{d s}, f=\frac{1}{2 \pi} \sqrt{\frac{k}{m}}=\frac{\sqrt{g}}{2 \pi} \sqrt{\frac{d F / F}{d s}}
\end{gathered}
$$

\section{Force characteristics optimization and comparison}

The relationship between levitation force, force density, force ripple and major structural parameters are analysed by finite element method in this section, which is conductive to the design and optimization of the tubular horizontal-gap passive magnetic levitation vibration isolator. The major structural parameters of four topologies of THPMLVI are shown in Fig. 2. The force characteristics like levitation force, force density, and force ripple are mainly influenced by major structural parameters like the width of stator magnets $d_{\mathrm{s}}, d_{\mathrm{s} 1}, d_{\mathrm{s} 2}, d_{\mathrm{s} 3}$, width of mover magnets $d_{\mathrm{m}}, d_{\mathrm{m} 1}, d_{\mathrm{m} 2}, d_{\mathrm{m} 3}$, thickness of stator magnets $h_{\mathrm{s}}$, and thickness of mover magnets $h_{\mathrm{m}}$. In addition, width of stator magnets $d_{\mathrm{s} 1}, d_{\mathrm{s} 2}, d_{\mathrm{s} 3}$ are expressed by stator magnet coefficient $\lambda_{\mathrm{s}}, d_{\mathrm{s} 1}=0.5\left(1-\lambda_{\mathrm{s}}\right) d_{\mathrm{s}}, d_{\mathrm{s} 2}=\lambda_{\mathrm{s}} d_{\mathrm{s}}, d_{\mathrm{s} 3}=\left(1-\lambda_{\mathrm{s}}\right) d_{\mathrm{s}}$, and width of mover magnets $d_{\mathrm{m} 1}, d_{\mathrm{m} 2}, d_{\mathrm{m} 3}$ are expressed by mover magnet coefficient $\lambda_{\mathrm{m}}, d_{\mathrm{m} 1}=0.5(1-$ $\left.\lambda_{\mathrm{m}}\right) d_{\mathrm{m}}, d_{\mathrm{m} 2}=\lambda_{\mathrm{m}} d_{\mathrm{m}}, d_{\mathrm{m} 3}=\left(1-\lambda_{\mathrm{m}}\right) d_{\mathrm{m}}$. The aforementioned design parameters are optimized with some structural parameters fixed, i.e., the radius of mover magnets is $40 \mathrm{~mm}$, considering the stroke and manufacturability, the air gap length is chosen to be $2.5 \mathrm{~mm}$, and in order to ensure low natural frequency $d_{\mathrm{s}}=d_{\mathrm{m}}$.

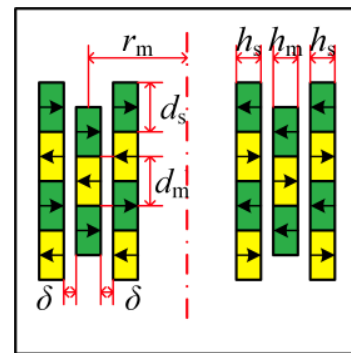

(a)

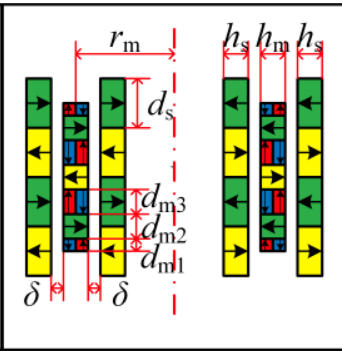

(b)

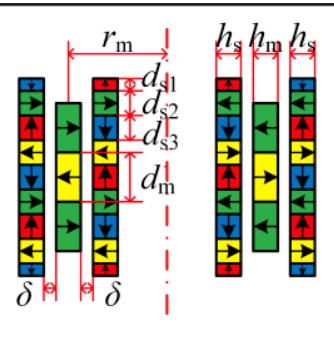

(c)

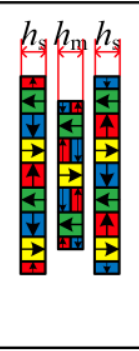

(d)

Figure 2. The major structural parameters of typical topologies of THPMLVI. 
For the NS-NS topology of THPMLVI shown in Fig. 2 (b), through changing the thickness of mover magnets $h_{\mathrm{m}}$ and width of stator magnets $d_{\mathrm{s}}$, the levitation force and force density are calculated as shown in Fig. 3. For a certain width of stator magnets $d_{\mathrm{s}}$, with the increase in thickness of mover magnets $h_{\mathrm{m}}$, the levitation force increases, the force density first increases and then decreases. The maximum fore density $11.72 \mathrm{~N} / \mathrm{cm} 3$ occurs when $h_{\mathrm{m}}$ and $d_{\mathrm{s}}$ are about $8 \mathrm{~mm}$ and $10 \mathrm{~mm}$, respectively. With the optimal width of stator magnets $d_{\mathrm{s}}$ of $10 \mathrm{~mm}$, the levitation force and force density with respect to the thickness of stator magnets $h_{\mathrm{s}}$ and thickness of mover magnets $h_{\mathrm{m}}$ are calculated, as shown in Fig. 3. For a certain thickness of mover magnets $h_{\mathrm{m}}$, with the increase in thickness of stator magnets $h_{\mathrm{s}}$, the levitation force increases, the force density first increases and then decreases. The maximum fore density $14.00 \mathrm{~N} / \mathrm{cm} 3$ occurs when $h_{\mathrm{m}}$ and $h_{\mathrm{m}}$ are about $4 \mathrm{~mm}$ and $6 \mathrm{~mm}$, respectively. Through changing the thickness of mover magnets $h_{\mathrm{m}}$, thickness of stator magnets $h_{\mathrm{s}}$ and width of stator magnets $d_{\mathrm{s}}$, the force ripple are calculated as shown in Fig. 3. With the increase in thickness of mover magnets $h_{\mathrm{m}}$, thickness of stator magnets $h_{\mathrm{s}}$, the force ripple is almost unchanged. With the increase in width of stator magnets $d_{\mathrm{s}}$, the force ripple decreases significantly.
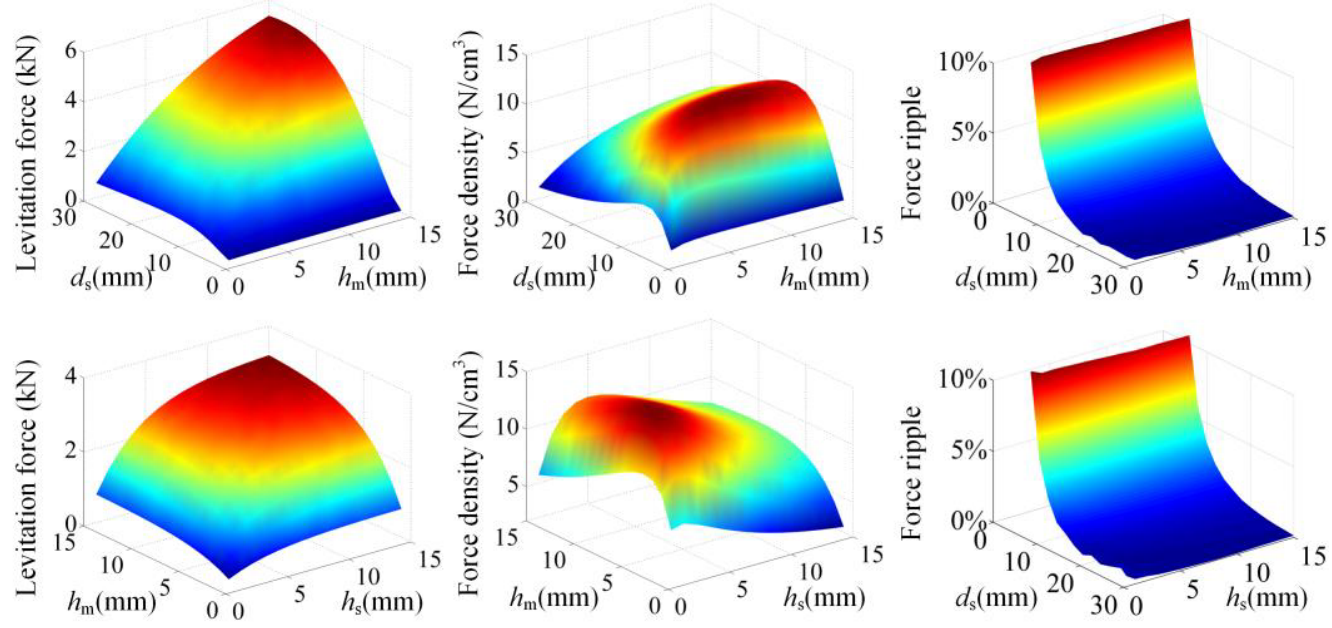

Figure 3. Force characteristics of NS-NS topology vs. $d_{\mathrm{s}}, h_{\mathrm{m}}$ and $h_{\mathrm{s}}$.

For the Halbach-NS topology of THPMLVI shown in Fig. 2 (c), through changing the thickness of mover magnets $h_{\mathrm{m}}$ and width of stator magnets $d_{\mathrm{s}}$, the levitation force and force density are calculated as shown in Fig. 4. For a certain width of stator magnets $d_{\mathrm{s}}$, with the increase in thickness of mover magnets $h_{\mathrm{m}}$, the levitation force increases, the force density first increases and then decreases. The maximum fore density $16.11 \mathrm{~N} / \mathrm{cm}^{3}$ occurs when $h_{\mathrm{m}}$ and $d_{\mathrm{s}}$ are about $12 \mathrm{~mm}$ and $9 \mathrm{~mm}$, respectively. With the optimal width of stator magnets $h_{\mathrm{m}}$ of $9 \mathrm{~mm}$, the levitation force and force density with respect to the stator magnet coefficient $\lambda_{\mathrm{s}}$ and width of stator magnets $d_{\mathrm{s}}$ are calculated, as shown in Fig. 4. For a width of stator magnets $d_{\mathrm{s}}$, with the increase in stator magnet coefficient $\lambda_{\mathrm{s}}$, both the levitation force and force density first increase and then decrease. The maximum fore density 16.58 $\mathrm{N} / \mathrm{cm}^{3}$ occurs when $d_{\mathrm{s}}$ and $\lambda_{\mathrm{s}}$ are about $12 \mathrm{~mm}$ and 0.4 , respectively. With the optimal $d_{\mathrm{s}}$ and $\lambda_{\mathrm{s}}$ of $12 \mathrm{~mm}$ and 0.4 , the levitation force and force density with respect to the thickness of stator magnets $h_{\mathrm{s}}$ and thickness of mover magnets $h_{\mathrm{m}}$ are calculated, as shown in Fig. 4. For a certain thickness of mover magnets $h_{\mathrm{m}}$, with the increase in thickness of stator magnets $h_{\mathrm{s}}$, the levitation force increases, the force density first increases and then decreases. The maximum fore density $19.46 \mathrm{~N} / \mathrm{cm}^{3}$ occurs when $h_{\mathrm{s}}$ and $h_{\mathrm{m}}$ are about $4 \mathrm{~mm}$ and $7 \mathrm{~mm}$, respectively. Through changing the stator magnet coefficient $\lambda_{\mathrm{s}}$, thickness of mover magnets $h_{\mathrm{m}}$, thickness of stator magnets $h_{\mathrm{s}}$ and width of stator magnets $d_{\mathrm{s}}$, the force ripple are calculated as shown in Fig. 11. For a certain width of stator magnets $d_{\mathrm{s}}$, with the increase in stator magnet coefficient $\lambda_{s}$, the force ripple decreases. With the increase in thickness of mover magnets $h_{\mathrm{m}}$, thickness of stator magnets $h_{\mathrm{s}}$, the force ripple is almost unchanged. With the increase in width of stator magnets $d_{\mathrm{s}}$, the force ripple decreases significantly. 

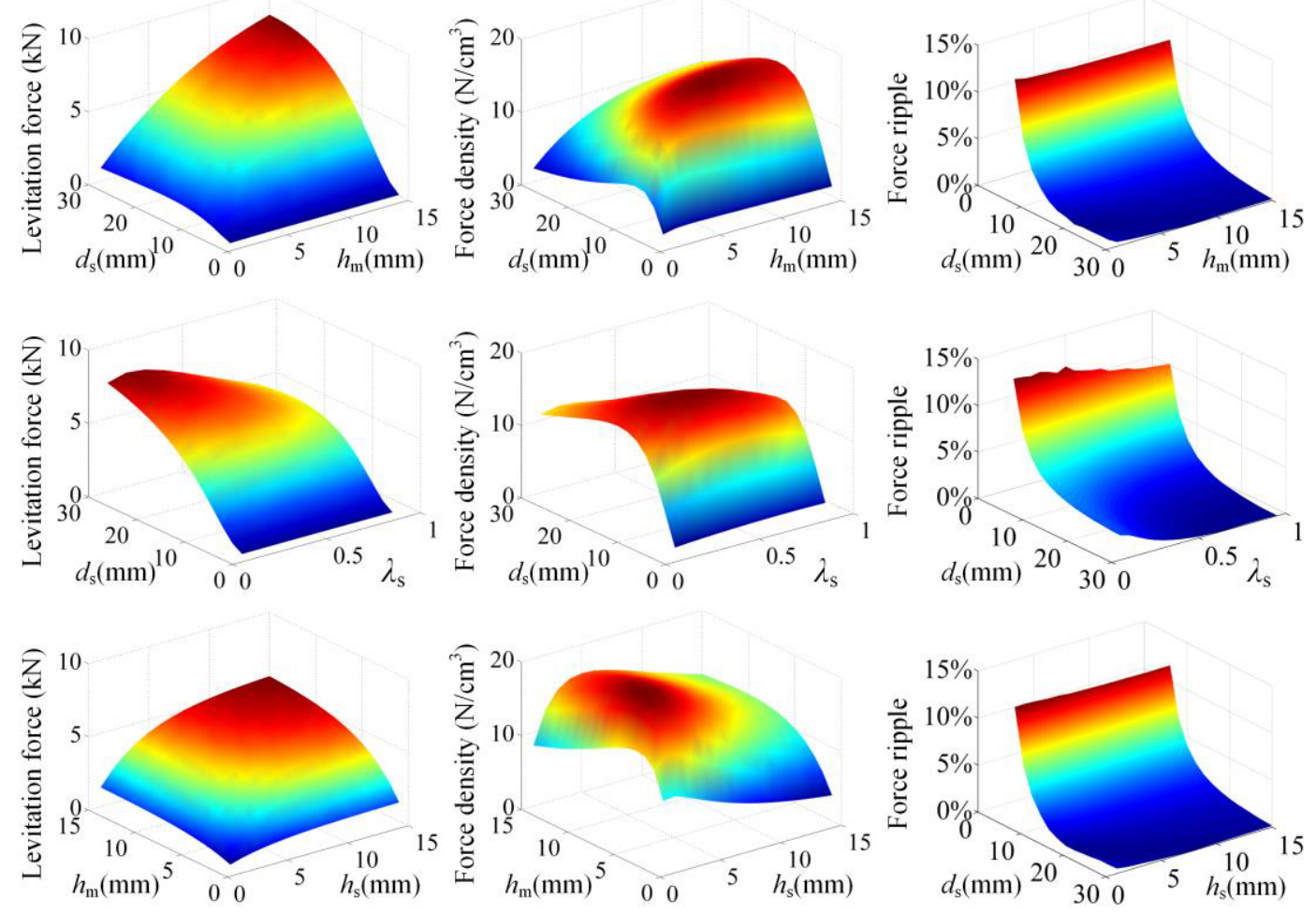

Figure 4. Force characteristics of Halbach-NS topology vs. $d_{\mathrm{s}}, h_{\mathrm{m}}, h_{\mathrm{s}}$ and $\lambda_{\mathrm{s}}$.

For the NS-Halbach topology of THPMLVI shown in Fig. 2 (d), through changing the thickness of mover magnets $h_{\mathrm{m}}$ and width of stator magnets $d_{\mathrm{s}}$, the levitation force and force density are calculated, as shown in Fig. 5. For a certain width of stator magnets $d_{\mathrm{s}}$, with the increase in thickness of mover magnets $h_{\mathrm{m}}$, the levitation force increases, the force density first increases and then de decreases. The maximum fore density $13.27 \mathrm{~N} / \mathrm{cm}^{3}$ occurs when $d_{\mathrm{s}}$ and $h_{\mathrm{m}}$ are about $10 \mathrm{~mm}$ and $11 \mathrm{~mm}$, respectively. With the optimal width of stator magnets $h_{\mathrm{m}}$ of $11 \mathrm{~mm}$, the levitation force and force density with respect to the mover magnet coefficient $\lambda_{\mathrm{m}}$ and width of stator magnets $d_{\mathrm{s}}$ are calculated, as shown in Fig. 5. For a width of stator magnets $d_{\mathrm{s}}$, with the increase in mover magnet coefficient $\lambda_{\mathrm{m}}$, both the levitation force and force density first increase and then decrease. The maximum fore density 13.26 $\mathrm{N} / \mathrm{cm}^{3}$ occurs when $d_{\mathrm{s}}$ and $\lambda_{\mathrm{m}}$ are about $10 \mathrm{~mm}$ and 0.6 , respectively. With the optimal $d_{\mathrm{s}}$ and $\lambda_{\mathrm{m}}$ of $10 \mathrm{~mm}$ and 0.6 , the levitation force and force density with respect to the thickness of stator magnets $h_{\mathrm{s}}$ and thickness of mover magnets $h_{\mathrm{m}}$ are calculated, as shown in Fig. 15. For a certain thickness of mover magnets $h_{\mathrm{m}}$, with the increase in thickness of stator magnets $h_{\mathrm{s}}$, the levitation force increases, the force density first increases and then decreases. The maximum fore density $15.29 \mathrm{~N} / \mathrm{cm}^{3}$ occurs when $h_{\mathrm{s}}$ and $h_{\mathrm{m}}$ are about $4 \mathrm{~mm}$ and $9 \mathrm{~mm}$, respectively. Through changing the mover magnet coefficient $\lambda_{\mathrm{m}}$, thickness of mover magnets $h_{\mathrm{m}}$, thickness of stator magnets $h_{\mathrm{s}}$ and width of stator magnets $d_{\mathrm{s}}$, the force ripple are calculated as shown in Fig. 5. For a certain width of stator magnets $d_{\mathrm{s}}$, with the increase in mover magnet coefficient $\lambda_{\mathrm{m}}$, the force ripple decreases. With the increase in thickness of mover magnets $h_{\mathrm{m}}$, thickness of stator magnets $h_{\mathrm{s}}$, the force ripple is almost unchanged. With the increase in width of stator magnets $d_{\mathrm{s}}$, the force ripple decreases significantly.

For the Halbach-Halbach topology of THPMLVI shown in Fig. 2 (e), through changing the thickness of mover magnets $h_{\mathrm{m}}$ and width of stator magnets $d_{\mathrm{s}}$, the levitation force and force density are calculated, as shown in Fig. 6. For a certain width of stator magnets $d_{\mathrm{s}}$, with the increase in thickness of mover magnets $h_{\mathrm{m}}$, the levitation force increases, the force density first increases and then de decreases. The maximum fore density $18.76 \mathrm{~N} / \mathrm{cm}^{3}$ occurs when $d_{\mathrm{s}}$ and $h_{\mathrm{m}}$ are about $12 \mathrm{~mm}$ and $14 \mathrm{~mm}$, respectively. With the optimal width of stator magnets $h_{\mathrm{m}}$ of $14 \mathrm{~mm}$, the levitation force and 
force density with respect to the stator magnet coefficient $\lambda_{\mathrm{s}}$ and width of stator magnets $d_{\mathrm{s}}$ are calculated, as shown in Fig. 19. For a width of stator magnets $d_{\mathrm{s}}$, with the increase in stator magnet coefficient $\lambda_{\mathrm{s}}$, both the levitation force and force density first increase and then decrease. The maximum force density $18.76 \mathrm{~N} / \mathrm{cm}^{3}$ occurs when $d_{\mathrm{s}}$ and $\lambda_{\mathrm{s}}$ are about $12 \mathrm{~mm}$ and 0.5 , respectively. With the optimal width of stator magnets $h_{\mathrm{m}}$ and stator magnet coefficient $\lambda_{\mathrm{s}}$ of $14 \mathrm{~mm}$ and 0.5 , the levitation force and force density with respect to the mover magnet coefficient $\lambda_{\mathrm{m}}$ and width of stator magnets $d_{\mathrm{s}}$ are calculated, as shown in Fig. 6 . For a width of stator magnets $d_{\mathrm{s}}$, with the increase in mover magnet coefficient $\lambda_{\mathrm{m}}$, both the levitation force and force density first increase and then decrease. The maximum fore density $18.99 \mathrm{~N} / \mathrm{cm}^{3}$ occurs when $d_{\mathrm{s}}$ and $\lambda_{\mathrm{m}}$ are about $12 \mathrm{~mm}$ and 0.6 , respectively. With the optimal $d_{\mathrm{s}}, \lambda_{\mathrm{s}}, \lambda_{\mathrm{m}}$ of $12 \mathrm{~mm}, 0.5,0.6$, the levitation force and force density with respect to the thickness of stator magnets $h_{\mathrm{s}}$ and thickness of mover magnets $h_{\mathrm{m}}$ are calculated, as shown in Fig. 6. For a certain thickness of mover magnets $h_{\mathrm{m}}$, with the increase in thickness of stator magnets $h_{\mathrm{s}}$, the levitation force increases, the force density first increases and then decreases. The maximum fore density $21.28 \mathrm{~N} / \mathrm{cm}^{3}$ occurs when $h_{\mathrm{s}}$ and $h_{\mathrm{m}}$ are about $4 \mathrm{~mm}$ and $9 \mathrm{~mm}$, respectively. Through changing the stator magnet coefficient $\lambda_{\mathrm{s}}$, mover magnet coefficient $\lambda_{\mathrm{m}}$, thickness of mover magnets $h_{\mathrm{m}}$, thickness of stator magnets $h_{\mathrm{s}}$ and width of stator magnets $d_{\mathrm{s}}$, the force ripple are calculated as shown in Fig. 6. With the increase in stator magnet coefficient $\lambda_{\mathrm{s}}$, mover magnet coefficient $\lambda_{\mathrm{m}}$, thickness of mover magnets $h_{\mathrm{m}}$, thickness of stator magnets $h_{\mathrm{s}}$, the force ripple is almost unchanged. With the increase in width of stator magnets $d_{\mathrm{s}}$, the force ripple decreases significantly.
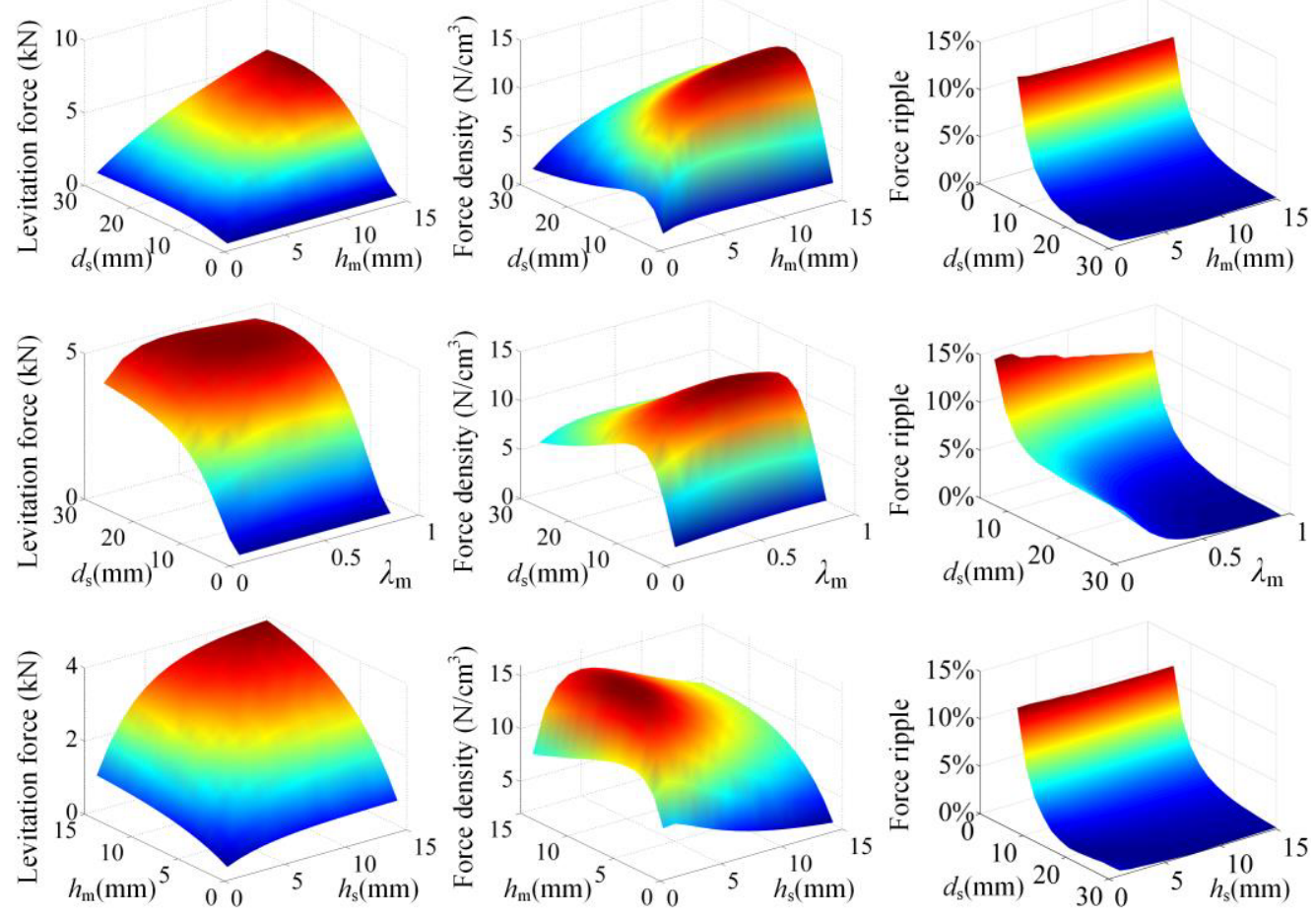

Figure 5. Force characteristics of NS-Halbach topology vs. $d_{\mathrm{s}}, h_{\mathrm{m}}, h_{\mathrm{s}}$ and $\lambda_{\mathrm{m}}$.

The maximum force density of NS-NS topology, Halbach-NS topology, NS-Halbach topology and Halbach-Halbach topology are $14.00 \mathrm{~N} / \mathrm{cm}^{3}, 19.46 \mathrm{~N} / \mathrm{cm}^{3}, 15.29 \mathrm{~N} / \mathrm{cm}^{3}$ and $21.28 \mathrm{~N} / \mathrm{cm}^{3}$, separately. It can be concluded that the Halbach-Halbach topology and Halbach-NS topology possesses much larger force density than NS-Halbach topology and NS-NS topology. This shows that the Halbach permanent magnet array on the stator can effectively increase the force density, but the Halbach permanent magnet array on the mover hardly increase the force density. This is because the Halbach permanent magnet array on the stator can effectively enhance the magnetic field, but the Halbach 
permanent magnet array on the mover suffers serious magnetic flux leakage. The minimum force ripple of NS-NS topology, Halbach-NS topology, NS-Halbach topology and Halbach-Halbach topology are nearly the same. The problem is that high force density and low force ripple can't be reached at the same time. This is because low force ripple requires large width of stator magnets $d_{\mathrm{s}}$ more than $30 \mathrm{~mm}$, but high force density requires width of stator magnets $d_{\mathrm{s}}$ about $10 \mathrm{~mm}$.
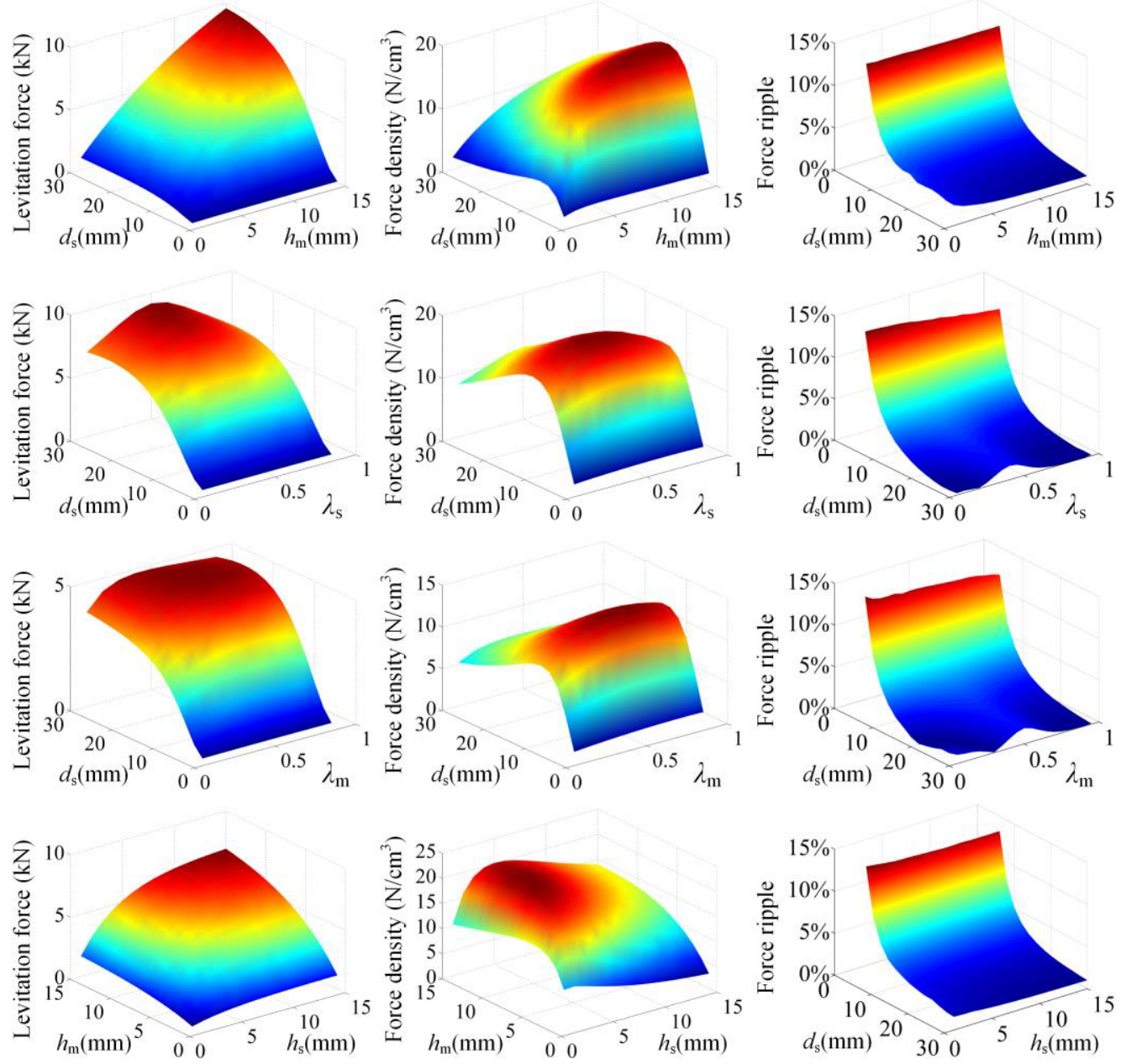

Figure 6. Force characteristics of Halbach -Halbach topology vs. $d_{\mathrm{s}}, h_{\mathrm{m}}, h_{\mathrm{s}}, \lambda_{\mathrm{s}}$ and $\lambda_{\mathrm{m}}$.

\section{Conclusions}

In this paper, a novel tubular horizontal-gap passive magnetic levitation vibration isolator (THPMLVI) has been investigated. The typical topologies and operation principle of THPMLVI are introduced. The analytical expression of magnetic force is derived. Further researches of the THPMLVI are taken under a finite element model. The relationship between levitation force, force density, force ripple and major structural parameters of the THPMLVI are analysed, which is conductive to the design and optimization of the THPMLVI. The force characteristics of four topologies of the THPMLV are compared and evaluated from the aspect of force density, force ripple and manufacturability, their major structural parameters are optimized to obtain higher high force density, which will reduce the volume of permanent magnet and the cost of THPMLVI. The following conclusions can be drawn: 
(1) For the topologies of the THPMLVI, the relationship of force density is as follows: HalbachHalbach topology $>$ Halbach-NS topology $>$ NS-Halbach topology $>$ NS-NS topology. The maximum force density of NS-NS topology, Halbach-NS topology, NS-Halbach topology and Halbach-Halbach topology are $14.00 \mathrm{~N} / \mathrm{cm} 3,19.46 \mathrm{~N} / \mathrm{cm} 3,15.29 \mathrm{~N} / \mathrm{cm} 3$ and $21.28 \mathrm{~N} / \mathrm{cm} 3$, separately. The Halbach permanent magnet array on the stator can effectively increase the force density.

(2) The minimum force ripple of NS-NS topology, Halbach-NS topology, NS-Halbach topology and Halbach-Halbach topology are nearly the same. High force density and low force ripple are contradictory.

(3) For the topologies of the THPMLVI, the order of good manufacturability is as follows: NS-NS topology $>$ Halbach-NS topology $>$ NS-Halbach topology $>$ Halbach-Halbach topology.

(4) The topology and major structural parameters of the THPMLVI should be determined according to the actual technical requirement, and the force density, force ripple and manufacturability should be taking into account at the same time.

\section{Acknowledgments}

This work was supported in part by the National Natural Science Foundation of China under Project 51507034 .

\section{References}

1. C. Hu, B. Yao, and Q.Wang, IEEE Trans. Ind. Electron., 58, 5195-5205 (2011)

2. L. Yu, C. Rao, and L. Du, Proc. ISECS 2nd Int. Conf. Comput.Contr. Manage., 368-371 (2009)

3. E. Puppin and V. Fratello, Rev. Sci. Instrum., 73, 4034-4036 (2002)

4. Y. Zhu, Q. Li, D. Xu, and M. Zhang, IEEE Tran. Magn., 48, 2228-2238 (2012)

5. W. Robertson, B. Cazzolato, and A. Zander, IEEE Tran. Magn., 41, 3826-3838 (2005)

6. W. Robertson, M. Kidner, B. Cazzolato, and A. Zander, J. Sound Vib., 326, 88-103 (2009)

7. W. Robertson, B. Cazzolato, and A. Zander, J. Sound Vib., 331, 1331-1341 (2012)

8. J. Janssen, J. Paulides, E. Lomonova, and B. Delinchant, J. Yonnet. Mechatronics, 23, 197-203 (2013)

9. D. van Casteren, J. Paulides, J. Janssen, and E. Lomonova, IEEE Trans. Ind. Appl., 51, 204-210 (2015)

10. D. van Casteren, J. Paulides, and E. Lomonova, Archives of Electrical Engineering, 64, 593-604 (2015)

11. Y. Zhu, Q. Li, D. Xu, C. Hu, and M. Zhang, Rev. Sci. Instrum., 83, 098108 (2012)

12. D. Xu, Q. Yu, J. Zhou, and S. Bishop, J. Sound Vib., 332, 3377-3389 (2013)

13. W. Wu, X. Chen, and Y. Shan, J. Sound Vib., 333, 2958-2970 (2014)

14. K. Shin. International Journal of Precision Engineering and Manufacturing, 15, 439-445 (2014)

15. Y. Zheng, X. Zhang, Y. Luo, B. Yan, and C. Ma, J. Sound Vib., 360, 31-52 (2016)

16. E. Fuilani, S. Reznik, and A. Kroll, IEEE Trans. Magn., 31, 844-851 (1995)

17. E. Fuilani, IEEE Trans. Magn., 29, 2295-2301 (1993) 